\title{
Preparation and Biocompatibility of Poly \\ (Methyl Methacrylate) Reinforced with Bioactive Particles
}

\author{
Marivalda de Magalhães Pereira ${ }^{\mathrm{a}}$, Rodrigo Lambert Oréfice ${ }^{\mathrm{a}}$, Herman Sander Mansur ${ }^{\mathrm{a}}$, \\ Miriam Teresa Paz Lopes ${ }^{\mathrm{b}}$, Regina Maria De Marco Turchetti-Maia ${ }^{\mathrm{b}}$, \\ Anilton Cesar Vasconcelos ${ }^{\mathrm{b}}$ \\ ${ }^{a}$ Departamento de Engenharia Metalúrgica e de Materiais \\ ${ }^{\mathrm{b}}$ Instituto de Ciências Biológicas, Universidade Federal de Minas Gerais, \\ Rua Espírito Santo 35/206, 30030-160 Belo Horizonte - MG, Brazil
}

Received:October 3, 2002; Revised: April 6, 2003

\begin{abstract}
Calcium phosphates and bioactive glasses have been used in many biomedical applications for more than 30 years due basically to their bioactive behavior. However, ceramics are too brittle for applications that require high levels of toughness and easy processability. In this work, a biphasic calcium phosphate (BCP) and a bioactive glass composition (BG) were combined with polymers to produce composites with tailorable properties and processability. The BCP particles were synthesized by a precipitation technique. The BG particles were produced by sol-gel processing. The $\mathrm{BCP}$ particles were treated with a silane agent to improve the compatibility between particles and the polymer matrix. Dense samples were produced by hot pressing $\left(200{ }^{\circ} \mathrm{C}\right)$ a mixture of $30 \mathrm{wt} . \%$ of particles in poly (methyl methacrylate). The samples produced were characterized by $\mathrm{X}$-ray diffraction, infrared spectroscopy and scanning electron microscopy. Mechanical properties were evaluated by a three point bending test. Samples were also submitted to in vitro bioactivity test and in vivo toxicity test. Results showed that the production of the composites was successfully achieved, yielding materials with particles well dispersed within the matrices. Evaluation of the in vivo inflammatory response showed low activity levels for all composites although composites with silane treated BCP particles led to milder inflammatory responses than composites with non-treated particles.
\end{abstract}

Keywords: biomaterials, composites, poly(methyl methacrylate), bioactive glass, calcium phosphate

\section{Introduction}

Several materials have been developed with the objective of regeneration or substitution of bone structures injured or lost by diseases or accidents. However, a gap remains to be filled since no synthetic material used until now presents characteristics close to the natural tissue, attending both biological aspects as well as mechanical requirements. Among these materials bioactive ceramics have been largely studied and used ${ }^{1,2}$, due to their osteoconduction properties and the ability of promoting the formation of a continuous bone-ceramic interface, therefore allowing an implant fixation mechanism. Bioceramics usually have mechanical properties quite different from those of natural tissues, particularly a high elastic modulus and a low toughness. This fact restricts the use of these materials in a wide range of applications. One alternative that is being considered and studied is the production of composites ${ }^{3-5}$. Polymer matrices reinforced with a bioactive phase can potentially combine the typical bioactive behavior of some bioceramics with mechanical properties closer to human tissues. In this work the polymer used to produce the composites was poly (methyl methacrylate) which has been largely used as a biomedical material ${ }^{6}$. In combination with ceramic particles it may produce composites with proper-

*e-mail: mpereira@ demet.ufmg.br

Trabalho apresentado no $1^{\circ}$ Congresso da Sociedade Brasileira em Materiais, Rio de Janeiro, Julho de 2002. 
ties closer to bone tissue. The composites were prepared using different bioactive ceramic particles, a bioactive glass (BG) and a biphasic calcium phosphate (BCP). In one type of composite produced the $\mathrm{BCP}$ particles were treated with a silane agent to improve the compatibility between particles and the polymer matrix. The goal of the study was to evaluate the structural and mechanical characteristics of these composites. Also the toxicity and the inflammatory response capability of these new composites were investigated. An in vivo test was performed by surgical implantation of the biomaterial in the subcutaneous tissue of mice, followed by histological studies in pre-established intervals of four, seven and fourteen days after the implantation, to evaluate the induced inflammatory response.

\section{Materials and Methods}

Commercial PMMA granules (from Metacril) was used as the polymer matrix. The bioceramic particles were produced as follows. All reagents used were analysis grade.

A bioactive glass with molar composition $60 \% \mathrm{SiO}_{2}$, $36 \% \mathrm{CaO}$ and $4 \% \mathrm{P}_{2} \mathrm{O}_{5}$ was synthesized by the sol-gel method. Tetraethylorthosilicate (TEOS), triethylphosphate (TEP) and tetra-hydrated calcium nitrate were used as the silica, phosphorous and calcium source respectively. The hydrolysis was performed in the presence of $2 \mathrm{~N} \mathrm{HNO}_{3}$ solution and $\mathrm{H}_{2} \mathrm{O}$ /TEOS molar ratio equal to 8 . The reagents were mixed for $1 \mathrm{~h}$ and the sol formed was cast in polyethylene containers. The samples were aged at $60{ }^{\circ} \mathrm{C}$, dried up to $170{ }^{\circ} \mathrm{C}$, and heat treated at $700^{\circ} \mathrm{C}$. For the preparation of the biphasic calcium phosphate particles calcium hydroxide and monobasic calcium phosphate solutions were mixed at ambient temperature for $30 \mathrm{~min}$, filtered and dried at $100{ }^{\circ} \mathrm{C}$ for $24 \mathrm{~h}$. The filter cake was heat treated at $1100{ }^{\circ} \mathrm{C}$ for $3 \mathrm{~h}$ and then ground.
The ground materials were separated in the 37 to $150 \mu \mathrm{m}$ range. Part of the BCP particles was immersed in a silane solution, filtered and dried before being mixed with the polymer material. The mixture of $30 \%$ weight of bioactive particles and PMMA was compression molded at $15 \mathrm{MPa}$ for $15 \mathrm{~min}$ at $170{ }^{\circ} \mathrm{C}$.

The bioactive particles and the obtained composite samples were analyzed by Scanning Electron Microscopy and $\mathrm{X}$-ray diffraction analysis (XRD). The mechanical behavior of the composites was evaluated by the three point bending test using samples $40 \times 5 \times 3 \mathrm{~mm}$ and $0.75 \mathrm{~mm} / \mathrm{min}$ cross head speed. Three samples of each condition were tested. To evaluate the bioactivity of the composites samples were immersed in a simulated body fluid (SBF) ${ }^{7}$ at $37{ }^{\circ} \mathrm{C}$ for different time periods. The surface area/volume ratio was fixed in $0.7 \mathrm{~cm}^{-1}$. The samples were analyzed by Fourier Transform Infrared Spectroscopy using the diffuse reflectance method (DRIFT).

The in vivo test to evaluate the toxicity and inflammatory response was performed in five weeks old mice, according to ASTM Standards F 763-87 and F 981-93. The animals, divided in three groups of five animals each, were previously dewormed with Porocin ${ }^{\circledR}$ and bathed with Triatox ${ }^{\circledR}$ for ectoparasite control, $48 \mathrm{~h}$ before the experiment. The animals were sedated with Diazepan ${ }^{\circledR}(8 \mathrm{mg} / \mathrm{kg}$, ie $240 \mu \mathrm{g} / 30 \mathrm{~g}$ ) via intra peritoneal and anesthetized with Thionembutal ${ }^{\circledR}(30 \mathrm{mg} / \mathrm{kg}$, ie $1 \mathrm{mg} / 30 \mathrm{~g})$ using the same route, with five minutes interval between them. The material was surgically implanted in the subcutaneous tissue of the interescapular region at the animal's back. Control incisions were also made in the caudal position. The animals were euthanized 4, 7 and 14 days after implantation. Histological sections of the materials-tissue interface were routinely processed and analyzed by optical microscopy.

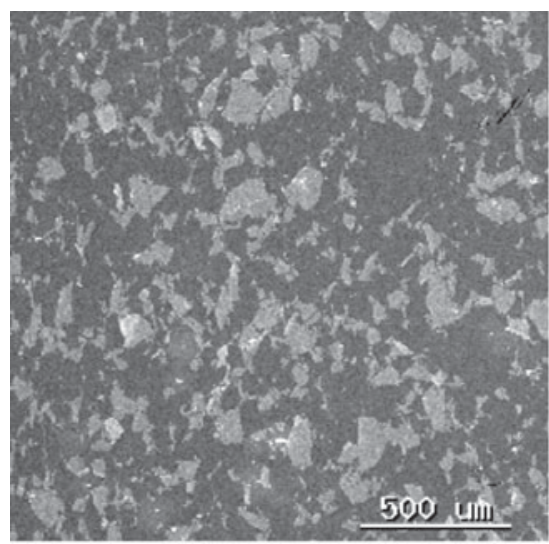

a)

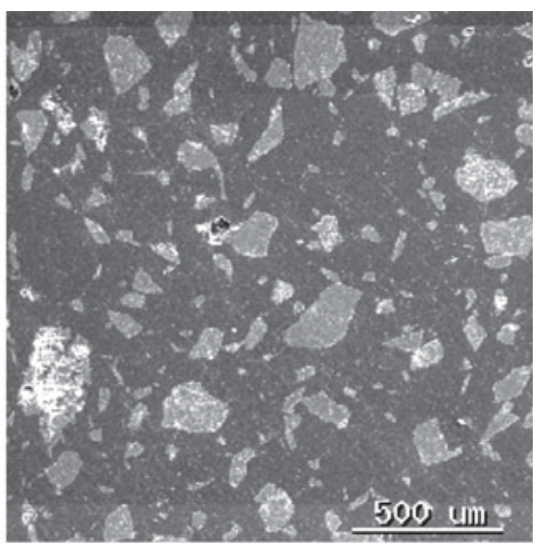

b)

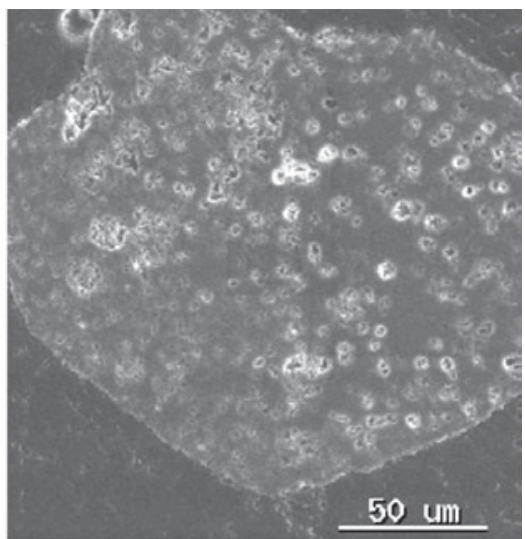

c)

Figure 1. SEM micrographs of a) PMMA/BG and b, c) PMMA/BCP composite samples. 


\section{Results}

Figure 1 shows SEM micrographs of the obtained composites revealing that their production was successfully achieved, yielding materials with particles well dispersed within the matrices. A higher magnification shows that the BCP particles have several pores or voids, probably originated during sample preparation, since small particles were observed in the solution during ultrasonic cleaning of the polished samples. This suggests that the sintering procedure was not efficient and that a higher sintering temperature may be necessary. The XRD spectra of the BCP particles presented in Fig. 2 indicates the presence of the two crystalline phases, hydroxyapatite (HA) and b-tricalcium phosphate (TCP). The proportion of the two phases present, determined based on the area under the peaks, is $80 \%$ HA and $20 \%$ TCP.

The mechanical properties of the composites determined by the three point bending test are presented in Table 1 . The stress $\times$ strain curve shows that the composites have a brittle behavior, similar to the polymer used. The introduction of the glass particles increased the elastic modulus compared to the polymer, as expected. The same behavior was not observed for the composites reinforced with BCP particles. All composites presented a decrease in strength relative to the polymer PMMA. This decrease in strength may be related to the presence of particles-matrix interfacial defects. No significant difference was observed in the mechanical properties of the composites produced with BCP particles treated with silane compared with composites containing no treated particles.

Some important applications of biomaterials are related to the replacement or repair of hard tissues that are not load carrier (such as in bones located at the face). For this type of application, biomaterials need to have stiffness similar to bone, so they can resemble bone for aesthetic purposes. On the other hand, they do not require high strength, since they will not be responsible for carrying load. In these cases, increasing the elastic modulus of polymers can have a positive impact in producing bioactive materials that combine bioactive behavior with elastic modulus comparable to bone. It is important to emphasize that other bioactive materials

Table 1. Mechanical properties of the composites, determined by tree point bending test.

\begin{tabular}{lcc}
\hline Material & Strength $(\mathrm{MPa})$ & $\begin{array}{c}\text { Elastic modulus } \\
(\mathrm{GPa})\end{array}$ \\
\hline PMMA & 91 & 1.7 \\
PMMA/BG & 64 & 6.0 \\
PMMA/HA & 38 & 1.4 \\
PMMA/HA/Sil & 33 & 1.3 \\
\hline
\end{tabular}

(such as hydroxyapatite and bioglasses) have elastic modulus too high, when compared to bone. Therefore, although a decrease in strenght compared to the pure polymer was observed, the increase in elastic modulus presented by the PMMA/BG composites leaded to materials closer in stiffness to bone and potential materials for non load bearing applications.

The FTIR spectra of samples before and after immersion in SBF are presented in Figs. 3 and 4. In the unreacted PMMA/BG composite samples the band present at $1700 \mathrm{~cm}^{-1}$ corresponds to the $\mathrm{C}=\mathrm{O}$ vibration related to the polymer matrix, the bands at 1100 and $482 \mathrm{~cm}^{-1}$ corresponds

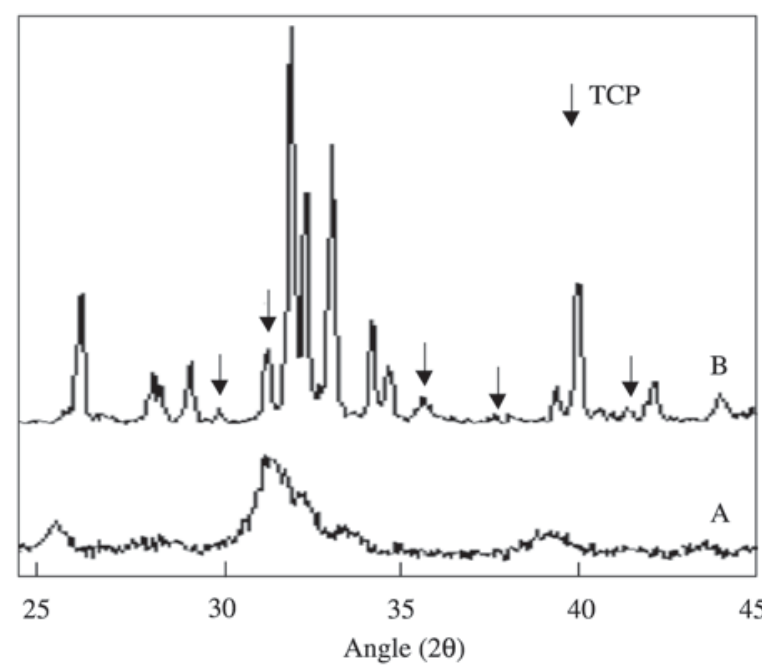

Figure 2. X-ray diffration spectra of BCP particles after drying at $100{ }^{\circ} \mathrm{C}$ (A) and after heat treatment at $1100{ }^{\circ} \mathrm{C}$ for $3 \mathrm{~h}$ (B). Peaks indicated by arrows correspond to tricalcium phosphate (TCP); other peaks correspond to hidroxyapatite (HA).

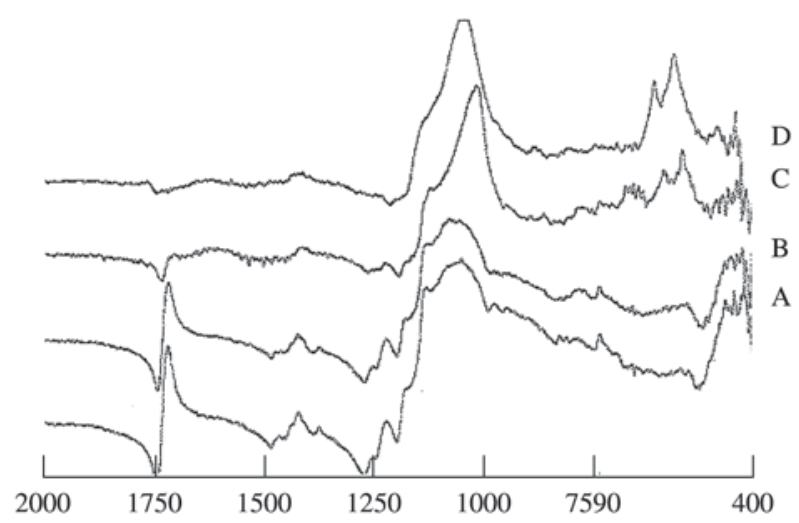

Figure 3. FTIR spectra of PMMA/BG composite before and after immersion in SBF for 0 (A), 1 (B), 6 (C) and $20 \mathrm{~h}$ (D). 


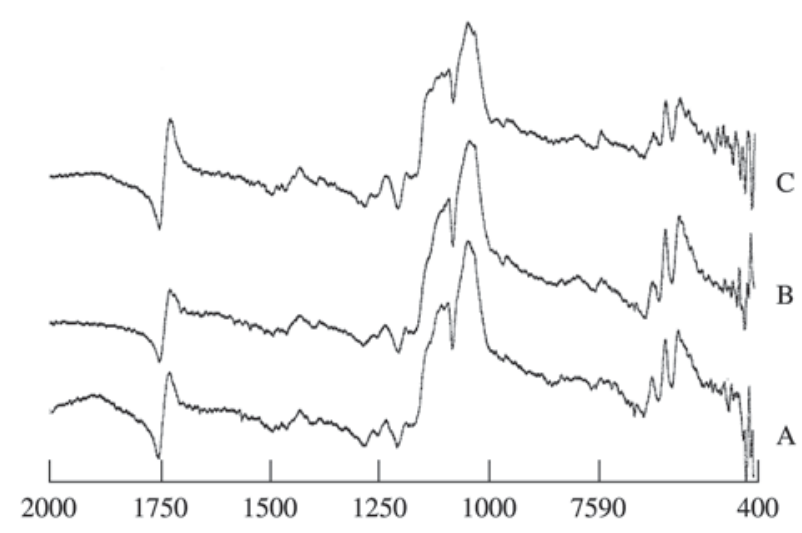

Figure 4. FTIR spectra of composites PMMA/BCP before and after immersion in SBF for 0 (A), 1 (B) and 8 weeks (C).

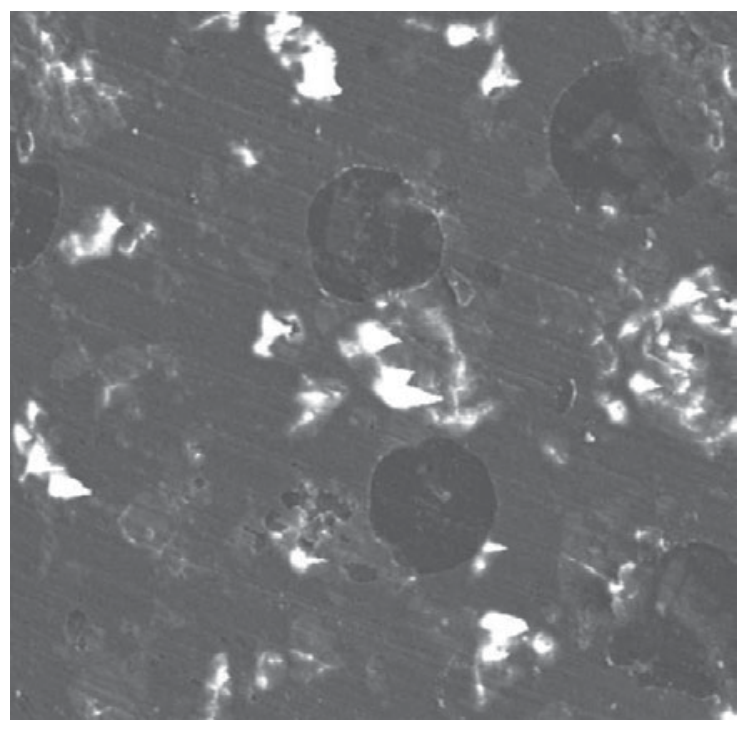

Figure 5. SEM micrograph of PMMA/BG composite after immersion in SBF for $20 \mathrm{~h}$. Magnification: $100 \times$. to the Si-O-Si stretching and bending vibrations respectively, characteristic of the glass particles. After immersion in SBF solution the major modifications observed are: a pronounced decrease in intensity of the bands related both to the polymer matrix and to the glass particles and the appearance of two bands at 598 and $566 \mathrm{~cm}^{-1}$, assigned as P-O bending vibrations, relative to the formation of a low crystallinity calcium phosphate layer. This layer is well established after $20 \mathrm{~h}$ immersion in SBF and was also observed by SEM analysis (Fig. 5). The formation of this layer in the early stages has been considered indicative of a high reactivity of the material and an indication of its bioactivity ${ }^{1,8}$.

In the case of the PMMA/BCP composites the triplet in the region of $602-550 \mathrm{~cm}^{-1}$, assigned as $\mathrm{P}-\mathrm{O}$ bending vibration, is characteristic of a crystalline hydroxyapatite, the major phase present in the PMMA/BCP composite. No significant modification in the FTIR spectra was observed after immersion in SBF, even after 8 weeks.

Histological sections showed a typical mild inflammatory response, with predominant fibroblasts and macrophages scattered involving the implant, with low activity levels and a quick resolution for all composites. Illustrative sections are shown in Fig. 6 for the PMMA/BG composites. At four days after the implantation a subacute inflammatory response was observed, but with mild cellular response. At seven days post surgery, the implanted material was surrounded by a fibrous capsule, with dense fibroplasia and active macrophages sometimes fused in giant cells containing fragments of the implanted material. At 14 days after the implantation the inflammatory response was practically well resolved with significant reduction in the number of macrophages.

Animals implanted with silane treated particles PMMA/ $\mathrm{BCP}$ composites showed milder inflammatory responses than composites with non-treated particles (Fig. 7). Therefore it was proposed that the silane treatment on particles

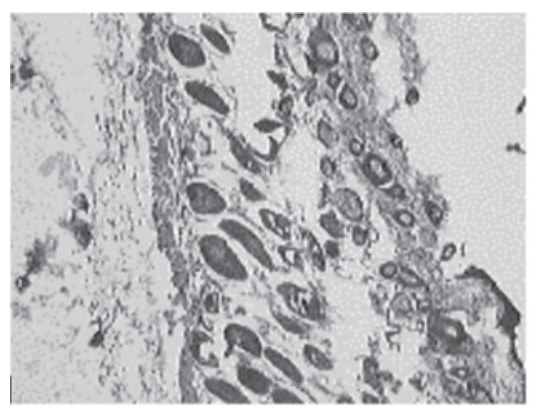

a)

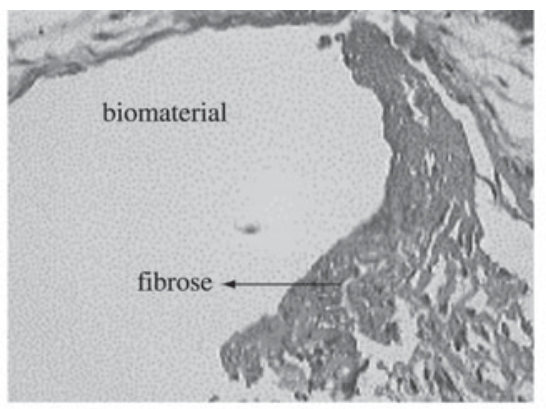

b)

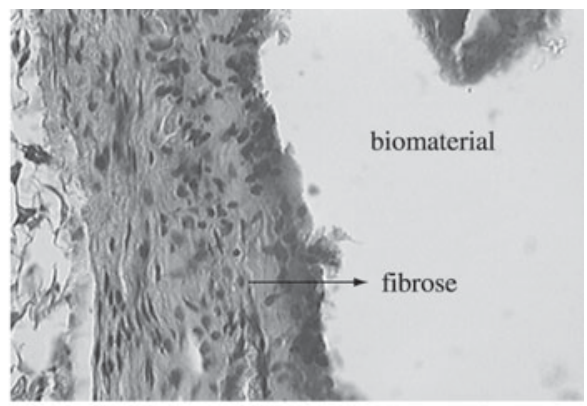

c)

Figure 6. Histological sections of tissue-implant interface formed after surgical insertion of PMMA/BG composite samples for 4 (a), 7 (b) and 14 (c) days. HE stain, magnifications: 40, 4 and 10x respectively. 


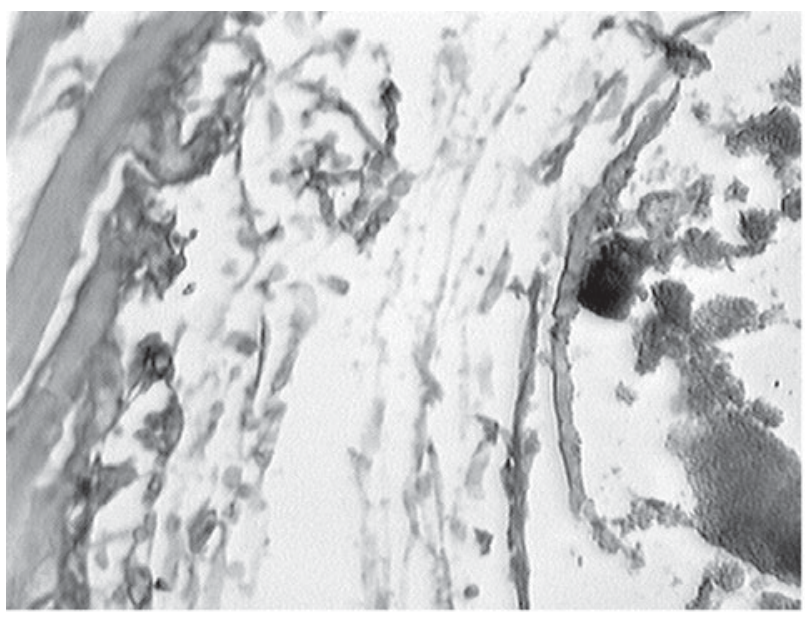

a)

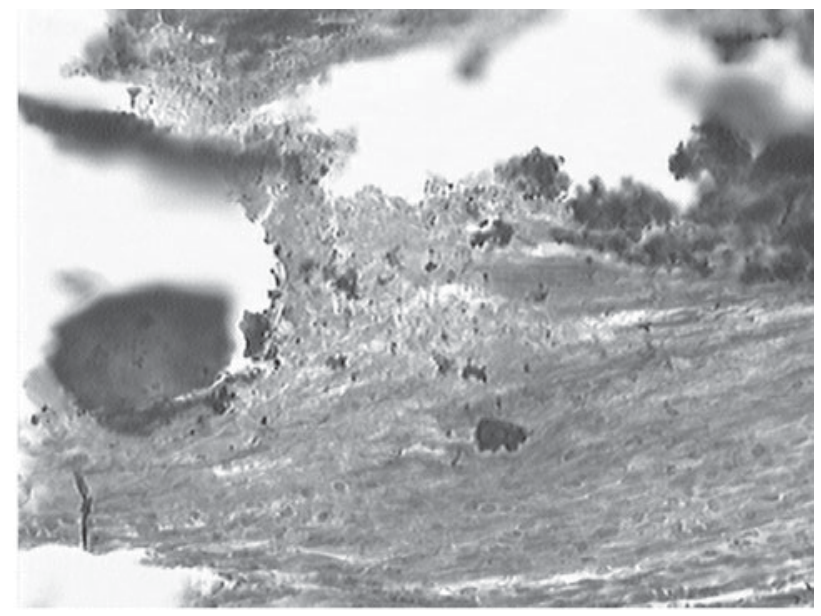

b)

Figura 7. Histological sections of tissue-implant interface after surgical insertion of PMMA/BCP (a) and PMMA/BCP/Sil (b) composite samples 7 days post surgery. HE stain, magnification $40 \times$.

improved their adhesion toward the polymer matrix, reducing particle pull out during in vivo test, resulting in improved biocompatibility.

The mild inflammatory response observed in the subcutaneous in vivo analysis show the non toxic nature of the materials produced. Further in vivo analyses of the PMMA/ $\mathrm{BG}$ composite interaction with bone tissue leading to bone bonding should be performed to confirm the bioactive nature of these composites.

\section{Conclusions}

The production of the composites was successfully achieved yielding materials with particles well dispersed within the matrices. The elastic modulus increased in the composites reinforced with BG particles but not in the composites reinforced with $\mathrm{BCP}$ particles. Although a decrease in strength compared to the pure polymer was observed, the increase in elastic modulus presented by the PMMA/BG composites leaded to materials closer to bone in terms of stiffness and potential materials for non load bearing applications.

The formation of an HCA layer in vitro was observed in the PMMA/BG composites indicating the high reactivity of the material and its bioactivity. Further in vivo analyses of this composite interaction with bone tissue leading to bone bonding should be performed to confirm the bioactive nature of the composites. Evaluation of the in vivo inflammatory response showed low activity levels for all composites, and their non toxic behavior. Composites with silane treated BCP particles led to milder inflammatory responses than composites with non-treated particles.

\section{References}

1. Hench, L J Amer Cer Soc, v. 8, p. 1705-1728, 1998.

2. Ducheyne, P.; Qiu, Q. Biomaterials, v. 20, p. 2287-2303, 1999.

3. Wang, M.; Hench, L.L.; Bonfield, W. Journal of Biomedical Materials Research, v. 42, p. 577-586, 1998.

4. He, D.; Jiang, B. J. Appl. Polym. Sci., v. 49, p. 617-621, 1993.

5. Bonfield, W. Proceedings of the $11^{\text {th }}$ International Symposium on Ceramics in Medicine, Bioceramics, v. 11, p. 37-40, 1998.

6. Mousa, W.F.; Kobayashi, S.S.; Kamimura, M. et al., Biomaterials, v. 21, p. 2137-2146, 2000.

7. Kokubo, T.; Kushitani, H.; Sakka S.; Kitsugi,T.; Yamamuro, T. J Biomed Mater Res, v. 24, p. 721-734, 1990.

8. Salinas, A.J.; Roman, J.; Vallet-Regi, M. et al., Biomaterials, v. 21, p. 251-257, 2000. 